\title{
Effect of Hypothyroidism in Sympathovagal Status of Post Menopausal Women
}

\author{
Authors \\ Dr Tazkira Begum ${ }^{1}$, Dr Aditya Ghosh², Dr S.M.I. Kabir ${ }^{3}$, Dr Wasima Jahan ${ }^{4}$ \\ ${ }^{1}$ Asst Prof, ${ }^{2}$ Demonstrator of Physiology, ${ }^{3}$ Medical Officer Obst \& Gynae, ${ }^{4}$ HOD \& Prof \\ ${ }_{1,2,3,4}$ Department Of Physiology, Assam Medical College, Dibrugarh 786002, Assam
}

\begin{abstract}
Introduction: Post menopausal women are more prone to hypothyroidism as well as for cardiovascular ailments. Autonomic dysfunction or sympathovagal imbalance may contribute to cardiovascular morbidity in postmenopausal hypothyroid patients.

Materials and Methods: Twenty healthy post menopausal women and twenty post menopausal women with hypothyroidism were enrolled for the study as control and cases respectively. Their autonomic status has been recorded as HRV for parasympathetic and hand grip test for sympathetic activity. Thyroid status was examined by RIA.

Result: Comparison of TSH level with HRV in both control and cases are found to be insignificant ( $P$ value 0.4317 and 0.3429 respectively). But the comparison between TSH with handgrip exercise is found to be significant in case group ( $P$ value $<0.0001$ and 0.0077) for both for systolic and diastolic BP.

Discussion: Though comparison between TSH with HRV of both control and cases are insignificant but the mean values of $R-R$ interval of $H R V$ decreases in cases than the control. So there is a vagal inhibition in hypothyroid group.
\end{abstract}

Conclusion: Sympathovagal imbalance due to sympathetic activation and vagal inhibition occurs in hypothyroidism.

Keywords: Autonomic nervous system, hand grip, HRV, hypothyroidism.

\section{INTRODUCTION}

There is an increasing prevalence of high levels of thyroid stimulating hormone (TSH) with age particularly in postmenopausal women. The symptoms of thyroid disease can be similar to postmenopausal complaints and are clinically difficult to differentiate. Although thyroid hormones have prominent effects on the heart and the peripheral vascular system either directly or indirectly which may be due to changes at the autonomic nervous system level, since thyroid hormone influences the autonomic nervous system $^{1}$. So, Autonomic dysfunction may contribute to cardiovascular morbidity in hypothyroid patients. It is controversial whether the abnormality exists in sympathetic or the parasympathetic function. It is also not known whether the severity of autonomic dysfunction is related to the degree of thyroid deficiency. There is scarcity in scientific documentation about autonomic function in subclinical hypothyroidism in post menopausal women. Kahaly et al, reported 
a hypofunctional parasympathetic system by analyzing time and frequency domains of heart rate variability $(\mathrm{HRV})^{2}$. A similar response was observed by authors who studied the heart rate response to exercise and recovery ${ }^{3}$ Galetta et al showed an increase in sympathetic tone with a decrease in HRV suggesting a decrease in vagal tone ${ }^{4}$ However Sahin et al suggested that in subclinical hypothyroid patients with TSH more than $10 \mathrm{mIU} / \mathrm{L}$ there was decrease in sympathetic tone and increase in parasympathetic activity ${ }^{5}$ .Thus the limited reports on subclinical hypothyroidism are themselves contradictory. These studies have compared subclinical hypothyroid patients with euthyroid controls and not hypothyroid patients. Many studies have reported improvement in autonomic function abnormalities following thyroxine treatment ${ }^{2,4,6}$. Present investigation has been done to evaluate and carry out a comprehensive study of autonomic functions in postmenopausal hypothyroid women and also to assess if there are any significant deviations from normal in sympathetic as well as parasympathetic reactivity in postmenopausal hypothyroid women.

\section{ETHICAL CONSIDERATION}

The necessary approval to conduct the study was obtained from ethical committee of Assam Medical College, Dibrugarh, Assam. Consent form obtained from all participants to ensure their voluntary participation.

\section{MATERIAL AND METHOD}

The study was conducted in Department of Physiology, Assam Medical college, Dibrugarh, Assam. Age group for the study was 50 TO 65 Years.

\section{Control: 20}

Cases: 20 (Postmenopausal hypothyroid women) The patients were selected on the basis of clinical features suggestive of decreased thyroid function, and laboratory findings of a normal free $\mathrm{T}_{3}$ and $\mathrm{T}_{4}$ levels and TSH more than $4.5 \mathrm{mIU} / \mathrm{L}$.

\section{Exclusion Criteria}

- Postmenopausal women with diabetes mellitus, renal disease, psychiatric disease, thyroid swelling, thyroid disorder or cardiovascular disease.

- Serum levels of TSH by RIA.

- For assessing parasympathetic activity $\rightarrow$ HRV analysis was done using the HRV analysis software version 1.1. Here Mean RR was measured in second(s).

- For assessing sympathetic activity Sustained Handgrip test was done by using handgrip dynamometer.

- Graph pad prism 5 were used for statistical analysis

\section{METHODS}

\section{$\mathbf{T}_{3}, \mathbf{T}_{4}$, TSH for thyroid function are analysed by radio immunoassay.}

Autonomic function testing was done by testing HRV and handgrip analysis. Before doing the ANS testing Patients were instructed to come after a light meal and to refrain from any caffeinated drinks on the day of testing. All testing of autonomic functions was done in the forenoon, after they were familiarized with the testing procedure.

\section{Basal Heart Rate Variability:}

After making the subject lie down in the supine position for 5 minutes, lead II ECG was recorded for 1 minute. Each R-R interval was determined. The minimum and maximum $\mathrm{R}-\mathrm{R}$ interval values were identified and converted into heart rate; and analysed in software version 1.1 .

\section{Sustained Handgrip Test}

The test was performed in the sitting position and the average of three basal blood pressure was taken. The maximum voluntary contraction was then determined with handgrip dynamometer using the dominant hand of the subject. Handgrip was then maintained at $30 \%$ of the subject's maximum capacity for 2-3 minutes. Blood pressure was recorded on the contra lateral arm 
every minute during contraction. The highest systolic and diastolic blood pressure during the handgrip exercise and the mean of the 3 blood pressure reading before the handgrip began were noted.

\section{RESULTS}

In our study, we observed that there were alterations in sympathetic as well as parasympathetic reactivity in postmenopausal hypothyroid women, when compared with normal established range of response to autonomic reactivity.

Table A: The distribution of mean and SD values of TSH, HRV and Handgrip analysis in cases and control

\begin{tabular}{|l|l|l|l|l|l|}
\hline Cases & Age & TSH & $\begin{array}{l}\text { R-R interval for } \\
\text { HRV }\end{array}$ & $\begin{array}{l}\text { Systolic BP in } \\
\text { Handgrip } \\
\text { dynaemometer }\end{array}$ & $\begin{array}{l}\text { Diastolic BP in } \\
\text { Handgrip } \\
\text { dynaemometer }\end{array}$ \\
\hline Control & $59.6 \pm 3.99$ & $2.26 \pm 1.17$ & $0.73 \pm 0.13$ & $9.7 \pm 6.05$ & $4.8 \pm 2.80$ \\
\hline Hypothyroid & $56.55 \pm 4.02$ & $9.17 \pm 5.60$ & $0.64 \pm 0.29$ & $7.25 \pm 5.54$ & $4.45 \pm 2.82$ \\
\hline
\end{tabular}

Table B: Correlation between TSH and HRV

\begin{tabular}{|l|l|l|l|}
\hline & MEAN VALUES of TSH & $\begin{array}{l}\text { MEAN VALUES of } \\
\text { HRV }\end{array}$ & P VALUE \\
\hline CONTROL & $2.26 \pm 1.17$ & $0.73 \pm 0.13$ & 0.4317 \\
\hline HYPOTHYROID & $9.17 \pm 5.60$ & $0.64 \pm 0.29$ & 0.3429 \\
\hline
\end{tabular}

Graph 1 Correlation between TSH and HRV
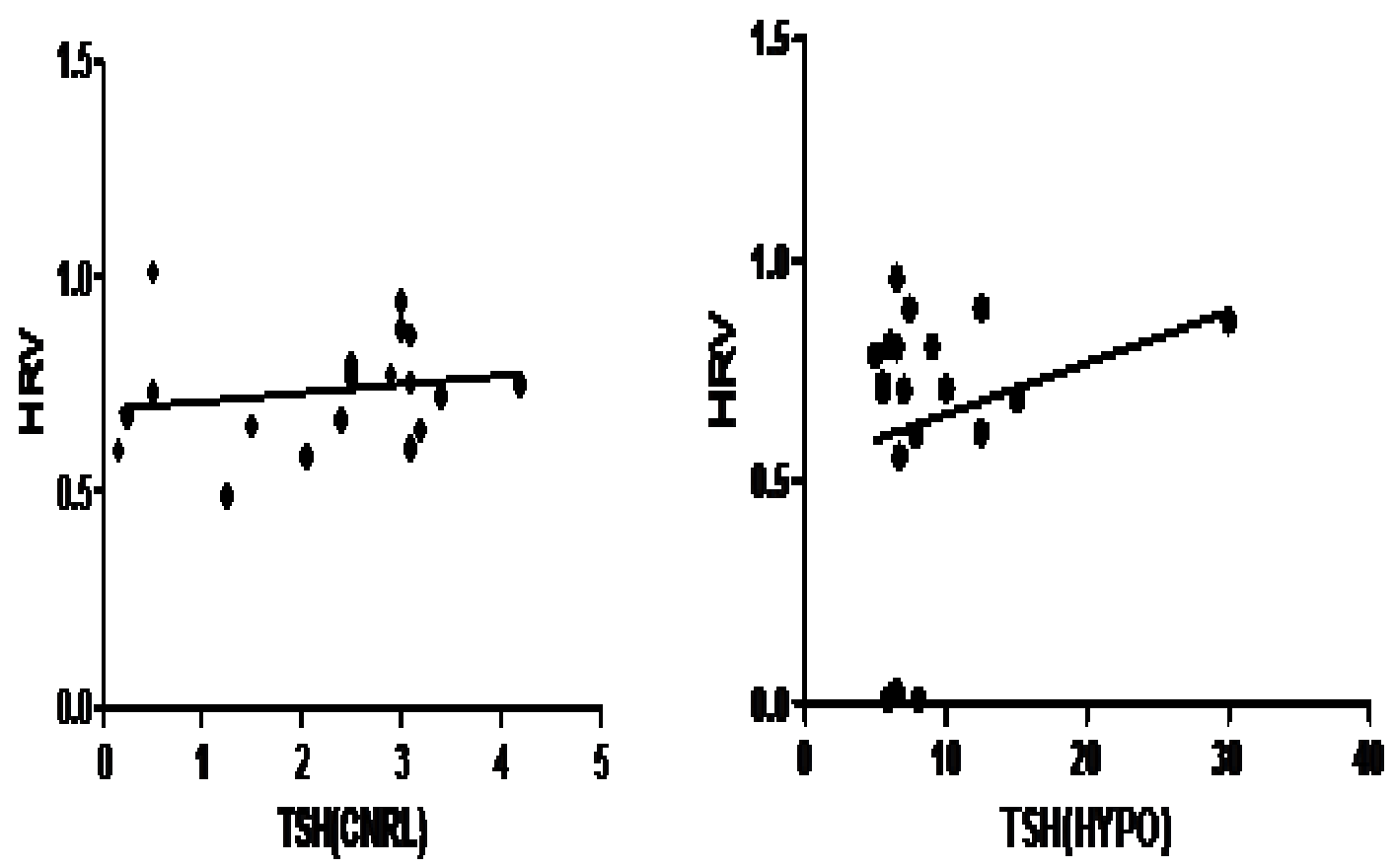

Table C: Correlation between TSH and DSBP:

\begin{tabular}{|l|l|l|l|}
\hline & MEAN VALUES of TSH & $\begin{array}{l}\text { MEAN VALUES of } \\
\text { DSBP }\end{array}$ & P VALUE \\
\hline CONTROL & $2.26 \pm 1.17$ & $9.7 \pm 6.05$ & 0.7530 \\
\hline HYPOTHYROID & $9.17 \pm 5.60$ & $7.25 \pm 5.54$ & $<0.0001$ \\
\hline
\end{tabular}


Graph 2: Correlation between TSH and DSBP
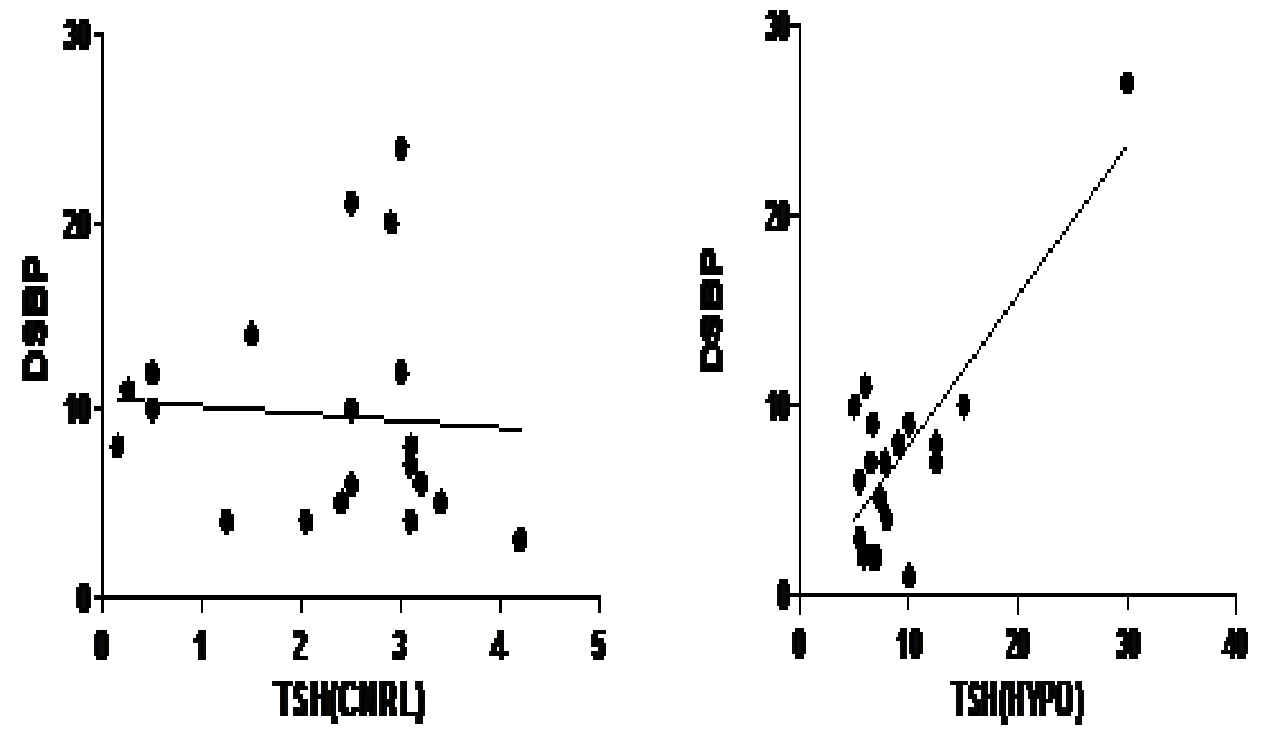

Table D: Correlation between TSH and DDBP

\begin{tabular}{|l|l|l|l|}
\hline & MEAN VALUES of TSH & MEAN VALUES of DDBP & P VALUE \\
\hline CONTROL & $2.26 \pm 1.17$ & $4.8 \pm 2.80$ & 0.7976 \\
\hline HYPOTHYROID & $9.17 \pm 5.60$ & $4.45 \pm 2.82$ & 0.0077 \\
\hline
\end{tabular}

Graph 3: Correlation between TSH and DDBP
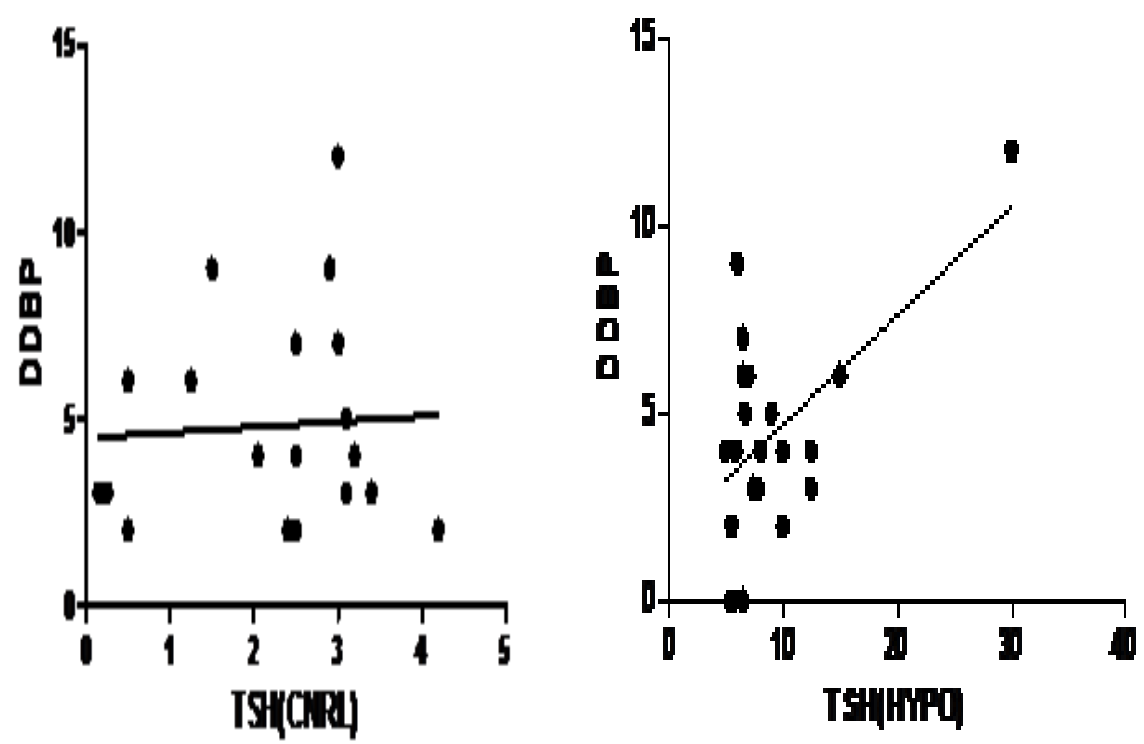

In Table A shows the mean and SD of TSH, HRV and handgrip test. here we can see that the mean R-R interval is less in cases than the control group.

Mean systolic and diastolic difference in BP less in cases than the control.

In table B comparison between TSH and HRV in both control and cases are not significant.

Comparison between TSH and DSBP in table C, in hypothyroid shows statistically significant. $\mathrm{P}$ value $<0.0001$

In table D comparison of TSH and DDBP in hypothyroid also shows statistically significant. P value is 0.0077 . 


\section{DISCUSSION}

In the present study, we found a significant reduction in R-R interval in hypothyroid patient than that of control group. It suggest increase sympathetic tone and decrease vagal tone in hypothyroid postmenopausal women. Vagal tone is an important determinant of cardiovascular health of an individual as it has profound influence on the control of heart rate, cardiac output and blood pressure ${ }^{7}$. Persons with poor vagal tone are more susceptible to cardiovascular diseases such as myocardial infarction, heart failure, and hypertension etc ${ }^{8,9}$. Thus, the present study indicates poor cardiovascular status in patients with thyroid dysfunction, as they were found to have severely decreased parasympathetic activity compared to control. In same way table $\mathrm{C}$ and $\mathrm{D}$, graph 2 and 3 shows that increase sympathetic activity in hypothyroid postmenopausal women in handgrip test. So in the graphs also there are positive corelation. Our findings support the report by Cacciatori et al that sympathetic influence on cardiovascular system is increased and vagal influence is decreased in hypothyroidism, which occurs secondary to adaptations to altered cardiovascular responses ${ }^{10}$, though it does not confirm the report of Xing $\mathrm{H}$ et al that the sympathetic activity does not change much in hypothyroidism ${ }^{11}$. But Cacciatori et al and Xing $\mathrm{H}$ et al the study group was reproductive age group. According to Motiva et $\mathrm{al}^{13}$ study, as females after menopause are more prone to cardiovascular complications .Further study should assess the degree and nature of SVI linked to cardiovascular dysfunctions in post-menopausal hypothyroid patient. So, our study correlates with Motiva et al study. Another study shows thyroid dysfunctions are more common in females especially in postmenopausal age group ${ }^{12}$. However, till date, no report is available on comparison of SVI exclusively in female postmenopausal age group. Therefore, in the present study we had solely assessed sympathovagal balance in thyroid dysfunctions in females of postmenopausal age group, which is a study of its first kind.

\section{CONCLUSION}

Therefore, in the present study we are trying to assess the sympathovagal imbalance in postmenopausal women with hypothyroidism. In our study we found that there is sympathetic over activity or vagal inhibition in post menopausal hypothyroid women. Since stronger vagal tone is a indicator of good health. So postmenopausal hypothyroid women are more prone to cardiovascular ailments with poor vagal tone. Further study should assess the degree and nature of SVI linked to cardiovascular dysfunctions in post-menopausal hypothyroid women.

\section{REFERENCE}

1. Foley CM, McAllister RM, Hasser EM. Thyroid status influences baroreflex function and autonomic contributions to arterial pressure and heart rate. Am J Physiol Heart Circ Physiol. 2001;280:2061-8.

2. Kahaly GJ. Cardiovascular and atherogenic aspect of subclinical hypothyroidism. Thyroid. 2000;10:66579. [PubMed]

3. Akcakoyun M, Emiroglu Y, Pala S, Kargin R, Guler GB, Esen O. Heart rate recovery and chronotropic incompetence in patients of subclinical hypothyroidism. Pacing Clin Electrophysiol. 2010;33:2-5. [PubMed]

4. Galetta F, Franzoni F, Fallani P, Rossi M, Carpi A, Rubello D, et al. Heart rate variability and QT dispersion in patients with subclinical hypothyroidism. Biomed Pharmacother. 2006;60:425-30. [PubMed]

5. Sahin I, Turan N, Kosar F, Taskapan C, Gunen H. Evaluation of autonomic activity in patients with subclinical hypothyroidism. J Endocrinol Invest. 2005;28:209-13. [PubMed]

6. Cacciatori V, Gemma ML, Bellavere F, Castello R, De Gregori ME, Zoppini G, et al. Power spectral analysis of heart rate in hypothyroidism. Eur J Endocrinol. 2000; $143: 327-33$ 
7. Task Force of the European Society of Cardiology and the North American Society of Pacing and Electrophysiology. Heart rate variability: Standards of measurement, physiological interpretation and clinical use. Circulation 1996; 93: 1043-1065.

8. Pal GK. Integrated regulation of cardiovascular functions. In: Textbook of Medical Physiology, 1st ed, New Delhi, Ahuja Publications, 2007; 654-657.

9. Haensel A, Mills PJ, Nelesen RA, Ziegler MG Dimsdale JE. The relationship between heart rate variability and inflammatory markers in cardiovascular diseases. Psychoneuroendocrinology 2008; 33: 1305-1312.

10. Cacciatori V, Gemma ML, Bellavere F, CastelloR, De Gregori ME, Zoppini G, Thomaseth K, Moghetti P, Muggeo M. Power spectral analysis of heart rate in hypothyroidism. Eur J Endocrinol 2000; 143: 327-333.

11. Xing H, Shen Y, Chen H, Wang Y, Shen W. Heart rate variability and its response to thyroxine replacement therapy in patients with hypothyroidism. Chin Med J 2001; 114: 906-908.

12. Demers LM, Spencer C. The Thyroid: Pathophysiology and thyroid function testing. In: Tietz textbook of clinical chemistry and 252 Karthik et al

13. Motivala AA, Rose PA, Kim HM, Smith YR, Bartnik C, Brook RD, Muzik O, Duvernoy CS. Cardiovascular risk, obesity, and myocardial blood flow in postmenopausal women. $\mathrm{J} \mathrm{Nucl}$ Cardiol 2008; 15: 510-517.Dis 2000; 181: 84628472 . 